\title{
Uma experiência sobre produção imagética e alteridade
}

\author{
Anelice Ribetto ${ }^{1}$
}

Valter Filé2

\section{Resumo}

Este ensaio é um primeiro exercício de pensamento sobre uma experiência que está acontecendo no mesmo tempo da escrita, portanto, traz nas suas entranhas os rabiscos, os titubeios, os balbuceios de palavras-conceitos apenas pensadas, apenas ensaiadas, apenas experimentadas. O trabalho que nos inspira é o projeto Narrar as experiências de alteridade na Educação, pensado para ser experimentado na disciplina de Estágio Supervisionado II do Curso de Pedagogia de uma faculdade pública brasileira. $\mathrm{O}$ objetivo desse projeto é possibilitar um exercício de pensamento sobre as formas de mostrar, fazer ver e dar a olhar as diferenças, especialmente nas imagens fotográficas produzidas pelos próprios alunos do curso.

Palavras-Chave: alteridade; imagens; estágio supervisionado.

1 Doutora em Educação pela UFF, Brasil. Professora do Programa de Mestrado em Educação da Faculdade de Formação de Professores da UERJ, Brasil. anelatina@gmail.com

2 Doutor em Educação pela UERJ, Brasil. Professor do Programa de Pós-Graduação Mestrado em Educação da UFRRJ, Brasil. valterfile@gmail.com 


\title{
An experience about imagetic and alterity production
}

\begin{abstract}
This essay is a first exercise of thinking about an experience that is happening at the same time of writing, therefore, brings in his bowels the scribbles, the hesitations, the bables word-concepts just thought, just tested, just experienced. The work that inspires us is the project "Narrating the experiences of alterity in Education", project designed to be experienced in the discipline Supervised Internship II in Pedagogy Course of a Brazilian public college. This project goal is to enable an exercise in thinking about ways to show, do and give a look to see the differences, especially in photographic images produced by own students in the course.
\end{abstract}

Keywords: alterity; images; internship supervised.

Difícil fotografar o silêncio. Entretanto tentei.

(Manoel de Barros, 2000, p.11)

\section{Os primeiros rabiscos... Sobre o projeto}

Esse projeto tem como principal antecedente um outro projeto experimental ensaiado no mesmo espaço de formação no ano de 2009. Esse primeiro projeto estava atravessado pelas palavras-conceitos "resistência" e "potência", pelas considerações de Jorge Larrosa sobre "experiência" (2001) e de Carlos Skliar sobre "alteridade" (2003) na Educação (que é) do outro a partir da possibilidade de nos experimentar como sujeitos - na cena pedagógica -, priorizando a discussão de aquilo que irrompe e interrompe como diferença e como acontecimento. Nesse sentido, interessava pensar os olhares do pesquisador, do educador, dos estudantes desde uma cena diferente daquela que tem privilegiado historicamente a mesmidade: tratava-se de pensar na resistência e potência de saberes, outros saberes, criados no cotidiano da Educação 
e as maneiras como os narramos. Essa experiência colocou no centro da conversa a pergunta "em que língua vamos contar aquilo que nos acontece?", pergunta inspirada em outro texto de Jorge Larrosa (2006b) e que derivou na produção de uma série de contos sobre as práticas pedagógicas dos alunos no próprio estágio. Já não mais descrever nossas observações sobre uma escola - quase sempre em falta -, mas narrar nossas experiências sobre as possibilidades de potência de uma escola que aparece, muitas das vezes, como (in)visível - no olhar do aluno - e que irrompe como acontecimento. Nessa experiência, algumas das alunas (se) narraram por meio de fotografias tiradas nas escolas de realização do estágio. Foi a partir dessa prática - não planejada - que o projeto atual foi sendo pensado, pois percebemos que, na maioria das vezes, as imagens, aparentemente, só revelavam um saber - sobre a escola: o saber que já se tinha. Ou seja, antes mesmo do encontro com o cotidiano escolar, as estagiárias tinham certeza do que ali encontrariam (e narrariam com palavras ou imagens), ou melhor, de tudo o que ali não encontrariam, pois as imagens e as falas se referiam - antecipadamente - a uma escola em falta, a uma escola incompleta, a uma escola deficiente etc.

Também como antecedente, alguns dos campos de saberes e experiências pelos quais transitamos - tensa e intensamente - desde alguns anos poderiam se definir, talvez, como espaços de estudos e trabalho com as diferenças. Nesses espaços, considerados muitas vezes como campos de alteridade, temos nos enfrentado frequentemente com a pergunta "quem é o outro?", para a qual as respostas que frequente e rapidamente têm sido dadas se referem a questões impregnadas de saberes (e imagens) sobre os chamados outros, saberes (e imagens) que repetidamente nos ensinam a incompletude, a deficiência, a anormalidade encarnada.

Pensando na possibilidade de trabalhar o estágio supervisionado como laboratório de experimentação de outras formas de narrar o encontro com os outros, organizamos o programa para acontecer no espaço de uma escola pública. Essa instituição funciona com turmas de ensino regular, classes especiais e salas de recursos multifuncionais que são as três formas de organização da educação especial, segundo a Política Nacional de Educação Especial na Perspectiva da Educação Inclusiva 
(BRASIL, 2008). Dessa forma, nossos alunos teriam a possibilidade de estagiar em espaços educacionais ditos inclusivos, habitualmente considerados espaços da educação especial.

Ainda que este ensaio não tenha como objetivo discutir os diferentes paradigmas do campo da educação especial ou, ainda, a tensão existente no ensino regular pela (re) significação da educação especial não mais como escola, mas como modalidade transversal do ensino brasileiro, é preciso dizer que esse é um campo em tensão e que

uma fronteira separa de forma muito clara aqueles olhares que continuam pensando que o problema está na "anormalidade"; de aqueles que fazem o contrario, isto é, que consideram a "normalidade" como o problema. As primeiras - só aparentemente mais científicas mais acadêmicas - seguem obsessivas por aquilo que é pensado e produzido como "anormal"; vigiando cada um dos desvios, descrevendo cada detalhe do patológico, cada vestígio da anormalidade e suspeitando de toda deficiência. Este tipo de olhar não é útil para a educação especial e nem para a educação em geral: o "anormalizam" tudo e a todos. Os outros olhares - talvez menos vigilantes, mas também menos pretensiosos - tratam de inverter a lógica e o poder da normalidade, fazendo de esse último, do normal, o problema em questão. (SKLIAR, 2005, p. 12)

É nessa perspectiva que nosso trabalho pretende se situar, tentando provocar uma desnaturalização do ato de olhar e uma pergunta contínua sobre a produção de imagens cotidianas de alteridade na relação com o outro.

Nesse sentido, a primeira intenção de trabalhar com essa produção como centro do estudo dessa disciplina foi fotografar - no estágio - aquilo que interrompa nossa tranquilidade de olhar, fazendo-nos ver (pensar, sentir) coisas que até então não tínhamos visto (pensado, sentido), ou seja, a produção de imagens como exercício de alteridade. Por quê? Talvez porque tenhamos a sensação, junto com Larrosa (2006a),

que tudo o que vemos não parece ser outra coisa que o lugar sobre o qual projetamos nossa opinião, nosso saber e nosso poder, nossa arrogância, nossas palavras e nossas idéias, nossas conclusões. É como se só fossemos capazes de olhares concluintes, de imagens concluintes. É como se todo se nos desse a ver encoberto de explicações. (p. 11) 
Para isso, convidamos a essa empreitada autores como Carlos Skliar, que nos possibilita pensar conceitos como alteridade e diferença, discutir a produção da normalidade e da anormalidade e deslocar esse debate para a criação de imagens dos outros (a maioria das vezes, anormalizados); Nuria Perez de Lara, nessa mesma perspectiva, ajuda a discutir "quem são esses outros" da educação; Jorge Larrosa, trazendo novamente a palavra "experiência" para nos perguntarmos se alguma coisa ainda passa conosco nos espaços educacionais, se alguma coisa ainda pode nos passar quando olhamos a cena pedagógica no estágio supervisionado, se alguma coisa ainda nos altera ao produzir imagens não esperadas; Manoel de Barros, que, com sua poesia, nos permite pensar se é possível fotografar aquilo que irrompe e interrompe, fotografar o acontecimento, pois "difícil fotografar o silencio" (BARROS, M., 2000, p.11) mas, entretanto, podemos tentar. Interessa-nos

multiplicar as formas de olhar, multiplicar as possibilidades de enxergar aquilo que as imagens produzem. Não se trata de pensar com quais imagens trabalho, quais imagens acompanham conteúdos ou quais imagens deveriam ser apresentadas, mas, talvez, trata-se das formas de olhar, dos modos em que ao olhar essas imagens produzimos algum tipo de sensibilidade, memória e pensamento. (SKLIAR, 2009, p. 1)

As leituras e conversas se dão ${ }^{3}$ durante nossos encontros na faculdade, bem como nas projeções e debates de filmes como Janela da alma e Só dez por cento é mentira ${ }^{5}$. A partir desses encontros, organizamos nossa ida pra escola e - em duplas - frequentamos diferentes espaços da escola. Esses encontros são narrados principalmente por meio de imagens e expostos nos encontros na faculdade, formando, assim, um grande caldeirão de narrativas, metáforas e imagens. Finalmente, uma das atividades organizadas dentro desse contexto formativo foi a Oficina Fotografar o (in)visível. A seguir, apresentaremos algumas questões que se desdobram desses encontros, leituras e conversas, uma contextualização do espaço-tempo de formação no qual a experiência acontece: o estágio

3 Usamos o verbo no presente, pois a experiência ainda está acontecendo.

4 Dirigido por João Jardim e Walter Carvalho (2001).

5 Dirigido por Pedro Cezar (2009). 
supervisionado; algumas considerações iniciais sobre as formas de mostrar, fazer ver e dar a olhar as diferenças. E, finalmente, algumas produções imagéticas, narrativas dos alunos participantes dessa experiência, reunidas sob o título de Fotografar o (in)visível e apresentadas em um jogo de quatro cenas:

O (in)visível presente...

Ver como se fosse a primeira vez...

O normal e o anormal...

O (des)importante... As coisinhas do chão da escola...

\section{O estágio supervisionado como espaço de experimentação}

A lógica hegemônica dos cursos de formação de professores durante boa parte do século XX se fundamentou na concepção epistemológica da racionalidade técnica. Nessa concepção, que coloca teoria de um lado e a prática de outro, configura-se uma relação de subordinação das disciplinas pedagógicas - consideradas disciplinas práticas -, em detrimento das teóricas - consideradas disciplinas científicas. Nessa mesma lógica, o Estágio Supervisionado foi sendo definido nos currículos dos cursos de Licenciatura até antes da vigência da LDB 9.394/96 (BRASIL, 1996) como uma disciplina de complementação.

No contexto da produção de discussões resultantes dos movimentos de redemocratização do Brasil, a questão teórico-prática da disciplina Estágio Supervisionado se tornou objeto de estudo e de projetos de diferentes autores (CANDAU; LELIS, 1999), que propõem sob diferentes formas a unidade entre teoria e prática. Essas autoras denunciam que as orientações do estágio eram dirigidas em função de atividades de programas a priori, sem que tenham surgido das discussões entre educador-educando, no cotidiano da sala de aula, da escola e da comunidade. Assim, o conhecimento da realidade escolar por meio dos estágios não favorecia o pensar sobre uma prática criativa e nem sobre uma formação focada na experimentação desse processo.

Implícito nesse modelo há uma marca do paradigma moderno que 
instituiu o conhecimento científico como conhecimento universal e acabado do mundo. O espaço de produção desse saber - teórico - seria a universidade. Colocando o Estágio Supervisionado nesse contexto, entenderemos porque ele foi assumido - numa consideração tecnicista e instrumental - como a instância em que os saberes teóricos seriam aplicados na prática. $\mathrm{O}$ espaço de produção de práticas - consideradas representações de crenças, tradições, preconceitos e senso comum - seria a escola. Assim, um dos efeitos produzido foi o entendimento do Estágio Supervisionado como um momento de aplicação de teorias, e não de implicação prática-teoria-prática.

Na contramão dessa lógica e tentando oferecer outra forma de aproximação dessa instância de formação, alguns movimentos vêm acontecendo, principalmente aqueles que ousam pensar a formação e a educação em si como experiências. É nesse movimento que os projetos que estamos apresentando se reconhecem como tais, o que significa começar a pensar como se dá nossa aproximação aos espaços nos quais a prática do estágio acontece: as escolas.

O que temos visto ao longo dessas experiências é uma recorrente prática discursiva e um repetitivo olhar que se empenha em nomear rápida e quase que automaticamente esses espaços como espaços de falta. Antes mesmo de se produzir o encontro entre nós - alunos e professores da universidade e das escolas - já está dito, já está certo aquilo que vamos encontrar e até as teorias que irão fundamentar nosso dizer faltoso. Entendemos que esse processo invalida a possibilidade de que "alguma coisa nos passe, nos aconteça" nesse encontro, no estágio. Se já sabemos o que vamos encontrar, o estágio se transforma só em um trâmite burocrático de produção de relatórios que precisam apenas ser carimbados e legitimados no final do período.

Entender o Estágio Supervisionado como espaço de experimentação significa, primeiro, colocar em questão nossos discursos e nossos olhares sobre a escola, sobre os professores, sobre as práticas pedagógicas. Perguntar-nos por que dizemos o que dizemos e vemos o que vemos. Para que alguma coisa nos passe no Estágio Supervisionado, necessitamos nos dispor, nos expor ao outro, para que alguma coisa irrompa 
como acontecimento não esperado e interrompa nossa tranquilidade discursiva, nosso olhar acomodado. Nesse sentido, Gadamer (1977) diz que a experiência significa "sempre um processo negativo, porque supõe uma negação do que já era sabido". (p. 428).

É o vivido o que deixa sua marca e provoca um efeito em nós. O vivido que deixa marca se faz por um choque com o previsto - por ser imprevisto, quebra nossas certezas - e nos afeta de uma maneira não planejada, impensada. E nos transforma.

Finalmente, pensamos que "estagiar" pode ser uma experiência de estranhamento e, como tal, pode ser também a experiência de relação com esse estranhamento. Assim, o fundamental não são nossas habilidades como coletores de "dados, caçadores de evidencias, especialistas em tratar, relatar e sintetizar informação mas, aquilo que nos nutre e nos prepara para viver a experiência [do estágio] e para perguntar sobre as questões pedagógicas das experiências que buscamos compreender" (PEREZ DE LARA, 2010, p. 68). O que nos interessa, nessa empreitada, é questionarmos o olhar acostumado, que sabe com antecipação aquilo que irá ver, entendendo que

Há centenas de explicações sobre como se constrói o olhar pedagógico e talvez seja necessário mencionar a tradição de entender a formação e o saber como posição de desigualdade (desigualdade de saberes, de idades, de experiências, de funções). Se bem o olhar oferece uma dualidade composta por focos e por bordes pouco explorados, sabemos que nas instituições educativas tomam-se decisões diariamente como produto da naturalização do olhar. Para além da linguagem técnica e especializada, para além dos laudos e historias, para além das avaliações e dos diagnósticos, para além, ainda, das relações no interior das aulas, notamos que certas decisões sobre quem poderá ou não poderá aprender, quem poderá ou não poderá incluir-se, quem poderá ou não poderá "ter" futuro, dependem muito mais de um jogo (muito serio, muito grave) de olhares. Olhares que têm a ver com o poder, é certo, mas também com a posição desde onde partem, do lugar onde se formam e dos sujeitos aos que vão direcionadas (SKLIAR, 2009, p. 13).

E repensar como têm sido produzidos esses relatos faltosos recriados por um olhar arrogantemente tecnicista com pretensões de se saber neutro, objetivo e, fundamentalmente, de que forma, com que imagens 
os outros (da educação) têm sido apresentados e as formas como temos olhado para eles.

\title{
3 As formas de mostrar, fazer ver e dar a olhar as diferenças
}

\author{
Si lo que hay ante una imagen es exposición, \\ la mirada es claramente una posición, un punto de partida, \\ una dimensión inaugural, \\ posee un valor de principio: revela la posición de quién mira, \\ desde dónde mira, qué altura se atribuye al mirar, \\ en cuál posición deja o ubica a quien es mirado. \\ No se trata tanto de mencionar su dispositivo biológico ni el aparataje \\ cultural que lo gobierna, \\ sino los modos de posicionarse al mirar y al mirarse. \\ SKLIAR (2009, p. 3-4)
}

Olhares... Imagens... Modos de se posicionar ao olhar e olhar(-se) em relação aos outros. Mas, quem são os outros? Quais são as respostas que historicamente têm sido dadas pra essa questão? Ou melhor, de que lugares de saber e poder têm sido narrados e apresentados esses outros da educação?

Em primeiro lugar, parece necessário retomar uma questão enunciada no começo desse texto e que diz respeito à forma que entendemos a questão da diferença, muitas das vezes identificada como anormalidade. Nossa empreitada é um esforço exatamente para perguntarmos já não pela anormalidade e por quem a encarna - dentre eles, os deficientes - mas radicalizar nossa pergunta pela normalidade. Questionar a normalidade. Entendemos com Skliar e Téllez (2008) que

A educação em geral não demonstra preocupação com as diferenças, mas com aquilo que poderíamos chamar de uma certa obsessão pelos "diferentes". Os "diferentes" obedecem a uma construção, uma invenção, são um reflexo de um processo que poderíamos nomear de "diferencialismo", isto é, uma atitude sem dúvidas racista - de separação e de diminuição de alguns traços, de algumas marcas, de identidades em relação a uma grande generalidade de diferenças. As diferenças não podem ser apresentadas e nem descritas em termos de melhor e pior, de bem ou mal, de superior ou inferior, positivas ou negativas, etc. são de modo irredutível, simplesmente diferenças [...] De fato, a pergunta 
não deveria ser que são e como são as diferenças mas, como se inventam e reinventam, cotidianamente os "diferentes". (p. 10-11)

Repetimos, como se inventam e se reinventam, cotidianamente os "diferentes"? Para melhor entender essa invenção, essa reinvenção das anormalidades e os lugares que historicamente foram produzidos para ela a partir de narrativas e imagens, é necessário instaurar a pergunta sobre a normalidade. Ao colocar nossa pergunta na construção da normalidade, de certa forma viramos o foco, a figura e o fundo, pois, durante muito tempo, as ditas anormalidades foram consideradas um problema individual, no máximo familiar. Nós colocamos a pergunta sobre a relação: quais são as relações históricas, políticas, culturais que necessitaram produzir outros para reforçar o Mesmo e com que imagens têm sido narrados esses outros?

A normalidade, e suas muitas expressões, é tida como verdade, certeza, como dado natural, como imagem de realidade, bem como o próprio conceito daquilo que é "natural", mas são apenas construções históricas em torno das quais uma série de discursos, de imagens, de poderes, e toda uma série de saberes se construiu e sedimentou. Assim

os deficientes construídos como outros da normalidade, mas necessários a essa normalidade, costumam ser pensados em outro plano, como não completamente humanos, como necessitados de proteção e tutela. Não falam por si, são objetos de fala, sujeitos de um discurso que não lhes pertence. As construções discursivas sobre eles partem do pressuposto de que eles não são, nem podem ser tão humanos como o - nós; de que são seres humanos incompletos, tortos ou desviados, projetos inconclusos, um devir mais que um ser. Suas existências se resumem à sua deficiência, ao seu corpo deficiente, disfuncional, não adaptado, grotesco ou, tão somente, diferente - tomado como simples dado biológico, desvinculado de toda produção sócio-histórico. (CLIMAÇO, 2010, p. 11)

Um dos investimentos mais fortes desse projeto se dá exatamente na possibilidade de - por meio do Estágio Supervisionado - criar um espaço de pergunta e questionamento sobre esses saberes, sobre essas narrativas, sobre essas imagens que mostram um outro anormal e que têm sido naturalizadas, a tal ponto que uma das alunas que frequenta a disciplina demonstrou, logo após da primeira ida à escola, seu espanto ao 
achar o lugar "limpo, arrumado, com pessoas que se manifestavam felizes e, sobretudo, bem comportadas... Eu pensei que esses alunos pulariam em cima de mim (como feras)" ${ }^{\prime \prime}$. A que aprendizagem obedeceria essa argumentação? Argumentação de uma aluna que está no último período do Curso de Pedagogia de uma faculdade de formação de professores?

Por isso, parece-nos muito mais oportuno começar pela experiência, por aquilo que nos passa no encontro com o outro, nas relações de alteridade, em vez de começar pelo caminho inverso: que alguém - o professor nos diga, do lugar do saber e poder, o quem são os outros. Apostar na experiência significa que talvez essa pergunta não tenha resposta certa nem programada, mas, apenas, continue pura pergunta. Porque, em princípio, "são aqueles e aquelas alunas que com seus modos de ser, de mover-se, de olhar, de sentir, de ouvir, de atender, de expressar-se enfrentam à pedagogia, porque fazem tremer seus princípios, com sua simples presença nas salas" (PEREZ DE LARA, 2009, p. 47). Ainda nos perguntando com a autora: o que produzem em mim suas presenças? Quais perguntas suas miradas evocam em mim? Por que pensar hoje sobre a relação com esses outros se eles sempre estiveram aí? “[...] o que sinto que muda em mim a experiência da relação com o Outro, ou seja, minha experiência da relação com meninos e meninas singulares pra quem essa palavra "Outro" reduz todas suas diferenças e singularidades à indiferença?" (p. 50).

\section{Fotografar o (in)visível}

Difícil fotografar o silêncio.

Entretanto tentei. Eu conto:

Madrugada a minha aldeia estava morta. Não se ouvia um barulho, ninguém passava entre as casas.

Eu estava saindo de uma festa.

Eram quase quatro da manhã. Ia o silêncio pela rua carregando um bêbado.

Preparei minha máquina.

O silêncio era um carregador?

Estava carregando o bêbado.

Fotografei esse carregador.

(Manoel de Barros - 2000, p.11)

6 Informação verbal. 
A primeira questão que nos ocorreu quando o oferecimento de uma "oficina" de fotografia para os (as) alunos(as) da disciplina de Estágio Supervisionado foi como trabalhar as diferentes e complexas questões da fotografia traçando um paralelo com as questões propostas pelo Estágio Supervisionado e com as questões que nos desafiam na pesquisa a partir das implicações entre visão e conhecimento? Dentro da mesma preocupação com a oficina, como chamar a atenção para a "cegueira produzida pelas imagens naturais", banalizadas e banalizáveis do mundo? A partir dessas questões, outras surgem como implicação das nossas limitações de ver o mundo, das nossas certezas. Implicação da nossa fé naquilo que sustentamos como sendo apenas do outro, já que a imagem o tem como referente. Ou seja, nossa fé em que a imagem que produzimos tem um só lado: o lado externo ao olho, exterior ao nosso corpo. Olho que vê, como supõem alguns, e apenas reproduz aquilo que se oferece ao visor da câmera. Pensa-se que fotografamos o que existe tal e qual se apresenta aos olhos de todos.

A fotografia, mais do que compor modelos geométricos, põe em marcha os meios visuais que passam a vigorar também como modelos cognitivos e perceptivos de uma época, de um determinado grupo social, de uma determinada cultura, de uma determinada maneira de ver o mundo. Depende não apenas de um aparato mecânico e um modelo (o referente), mas daquilo que preexiste ao ato de fotografar, ou seja, aquilo que diz respeito à subjetividade do fotógrafo e que vai incidir sobre as suas decisões sobre o que mostrar e/ou o que esconder. Nenhum ato de fotografar pode ser considerado como um ato banal, sem referentes, isolado em si mesmo. Esse ato revela a reação do fotografo ao que se apresenta a ele numa determinada circunstância, num determinado tempo-espaço. O que se apresenta para ser traduzido, para ser registrado, para ser "revelado", para ser (re)criado. Como reagimos a esses momentos? De que são feitas as nossas escolhas? Que cenas construímos e que modelos de sociedade elas se prestam a mostrar e a que visões de mundo elas contribuem para reforçar ou para borrar?

A oficina não pretendia ser uma aula expositiva com textos, leituras e debates sobre o que foi lido. Pretendíamos experimentar alguns exercícios 
onde cada um(a) pudesse expor(se) ao mostrar o que podiam "ver", ao mostrar os limites do olhar e as dificuldades de exercitarem outras posições para o corpo, outras posições frente ao que se apresenta, aos acontecimentos.

Começamos mostrando algumas imagens e tentando relacionar alguns conceitos e algumas técnicas fotográficas mais clássicas aos problemas que estão sendo trabalhados no Estágio Supervisionado. Propusemos, de saída, a problematização do "ponto de vista", o lugar onde cada um(a) se coloca frente às situações que se dão a ver - tanto como fotógrafos, quanto como estagiários ou como pesquisadores.

Depois, propusemos um exercício (que poderia ser feito com câmeras digitais, celulares ou qualquer outro aparato de produção de imagem): pedimos para que cada um(a) saísse da sala onde acontecia a oficina e fosse produzir imagens sobre a universidade. E que, no momento do clique, pensassem na "posição" que estavam "assumindo" frente ao "assunto"7. Isso porque, quando nos colocamos numa posição, mostramos as coisas de uma maneira. Diferentes posições (diferentes pontos de vista) mostram as coisas de diferentes maneiras. Dessa forma, as diferentes maneiras de mostrar aquilo que se nos apresenta, talvez desestabilize a ideia de que só existe uma possibilidade de mostrar, uma possibilidade de ver, uma possibilidade de "ser". Pedimos que cada pessoa se "observasse" fotografando. Observasse, questionasse e desnaturalizasse os pontos de vista mais cômodos. Que se deslocassem (procurando, avaliando, experimentando), que se abaixassem, que subissem em coisas, que desestabilizassem a postura supostamente natural do corpo. Imaginemos como não devem ter reagido os corpos, pois tendemos a ver o mundo sempre em posição ereta, na "posição" mais cômoda. No ato fotográfico (e, às vezes, também na pesquisa, na vida em geral), muitos não costumam implicar o corpo e as suas condições de conforto e padecimento como custos das tomadas de posição, das tomadas de decisão. $\mathrm{O}$ clique pode ser pensando, no seu antes, pela tomada de posição - que inclui a escolhas dos ângulos, do enquadramento etc. - e pelo momento da compressão do dedo sobre o botão da câmera fotográfica, que é a conjugação da tomada de posição com uma decisão.

7 Em linguagem fotográfica, assunto é o que vai ser fotografado. 
Na volta da atividade, ao mostrarem as fotos, pedíamos para que as pessoas falassem sobre o ato de fotografar, tentando dar conta das seguintes questões: será que a partir de um lugar comum, de uma cena familiar (o lugar que muitos convivem diariamente), é possível mostrar alguma coisa que ainda não foi vista? E, mais do que isso: como mostrar de outras maneiras o que todos já viram e veem? Como mostrar o banalizado de outra forma, oferecendo oportunidades de ampliação das formas de ver aquele "assunto"? Como mostrar de forma que a imagem criada atue contra a banalização do olhar, contra a banalização do que se vê, ou ainda, contra a diminuição da capacidade de ver?

Trabalhamos, ainda, a relação entre o "ponto de vista" e aquilo que se queria mostrar. Insistimos que se abdicamos da problematização do nosso "ponto de vista", se nos conformamos (e nos confortamos) em dar a ver aquilo que todos já sabem e já viram (já que sempre se trata do assunto "narrado" da mesma maneira), talvez estejamos perdendo a oportunidade de mostrar de outras maneiras as coisas que já foram vistas, que já se sabe o que são, pois sempre são vistas a partir do mesmo lugar ocupado pelo(a) fotógrafo(a). Assim, vamos ficando cegos de tanto ver (o mesmo), diria Caetano Veloso. Ao passo que buscar outras possibilidades de dar a ver - questionando nosso ponto de vista, o que colocamos dentro do quadro e o que deixamos de fora, questionando o ângulo que adotamos -, sugerimos a possibilidade de vermos algo que nos surpreenda, que não havia sido visto/pensado ainda - no já visto, no familiar que seja. Mas, mais do que isso, sugerimos que é possível ver de muitas maneiras, dar a ver de muitas maneiras. Talvez essas sejam as possibilidades de enfrentarmos a cegueira causada pela profusão de imagens do mesmo. E a profusão de imagens do mesmo, muitas das vezes, privilegia pontos de vista hegemônicos, ajudando a reforçar determinados padrões de beleza, determinados estereótipos que ajudam a dar mais ênfase numa chamada "normalidade", determinadas formas de se ver o mundo. Ou seja, uma "didática" que contribui para a domesticação do nosso olhar e a "reconhecer as formas de ver corretas", que nos fazem rejeitar (ou, no mínimo, estranhar, negando) outros tipos de imagem, certas cenas, certas narrativas?

Talvez o importante das fotografias não seja a produção de verdades, 
muitos menos pela suposta representação da realidade que ela insiste em sugerir. Mas o que pode nos importar talvez seja a sua condição de nos fazer pensar, de possibilitar a criação de outras narrativas que nos inspire para outras ordens de percepção e experiências.

Muitas imagens foram produzidas. Algumas delas mostramos a agora.

\section{Primeira cena: o (in)visível presente}

Essa atividade - cena - foi a proposta da Oficina de Fotografia.

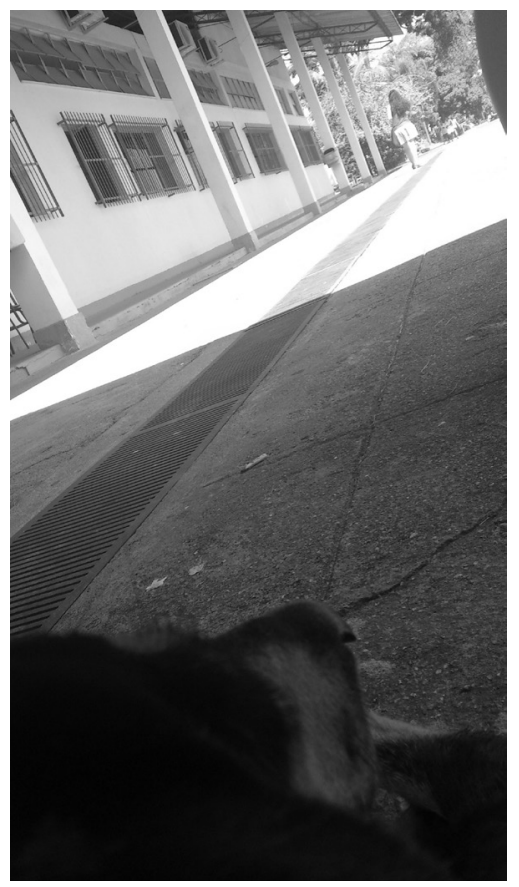

Imagem 1 .

Texto Imagem 1: a "outra ffp" - fotografia da aluna P.: "eu escolhi fotografá-la no ponto de vista dos cachorros, afinal, são quatro anos aqui e já estou doida pra sair correndo, e eles? Como veem esse lugar que lhe proporcionam tanto aconchego que os fazem ficar?" 


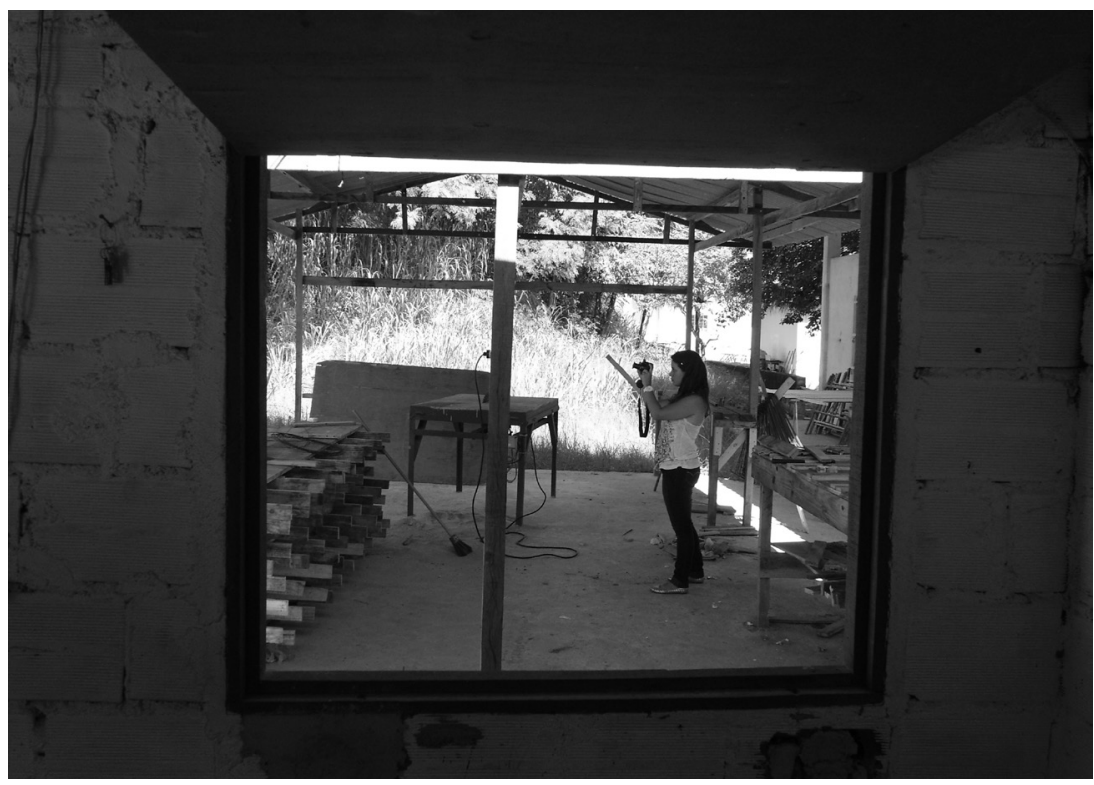

Imagem 2.

Texto Imagem 2: O invisível da faculdade no visível. Fotografia da aluna L.: "na verdade, eu queria fotografar uma plantação de quiabo que há dentro da obra da faculdade... uma faculdade que não vemos habitualmente... a fotografia é a fotografia de alguém fotografando os quiabos: na imagem o invisível - os quiabos - estão presentes..."

\section{Segunda cena: ver como se fosse a primeira vez}

Essa atividade foi proposta a partir da citada entrevista feita a Carlos Skliar (2009) e fundamentalmente a partir de uma fala dele:

Gosto muito de uma escrita do poeta Alberto Caeiro: a oposição entre olhar pela primeira vez e conhecer. Como se o fato de conhecer impedisse a possibilidade de olhar algo pela primeira vez. Como se conhecer fosse se negar a ver. Como se conhecer fosse deixar de se surpreender, abandonar a afeição que provoca em nós o olhado... Para mim, "educar o olhar" tem a ver, também, com educar para recuperar um olhar talvez infantil, talvez ingênuo, mas para nada primitivo: um olhar de surpresa, de implicação, de envolvimento com o visto. (p. 2) 


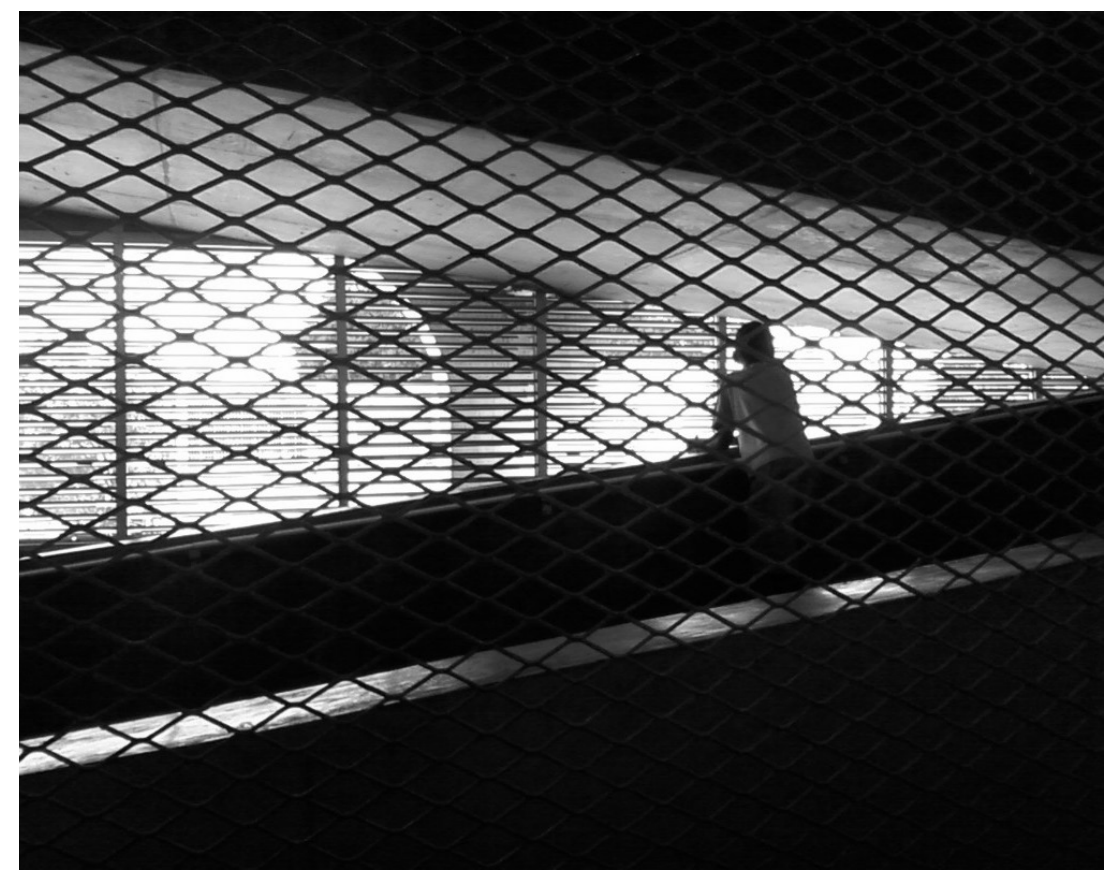

Imagem 3

Texto Imagem 3: "a escola como eu nunca vi..." Fotografia da aluna C.

\section{Terceira cena: o normal e o anormal}

A atividade foi pensada para problematizar, ou melhor, perguntarnos sobre a construção da anormalidade a partir da categoria de normalidade e como possibilidade de um outro olhar para essa criação. Talvez porque

Acreditamos que a educação especial poderia ser pensada como um discurso e uma prática que torna problemática e insustentável a ideia do "normal" corporal, do "normal" da língua, do "normal" da aprendizagem, do "normal" da sexualidade, do "normal" do comportamento, etc. [...] Sim aquilo que chamamos de educação especial não serve para colocar em dúvida "a normal", "o normal", "a normalidade", pois, então, não tem razão de ser nem maior sentido sua sobrevivência como campo. (SKLIAR, 2005, p. 41) 


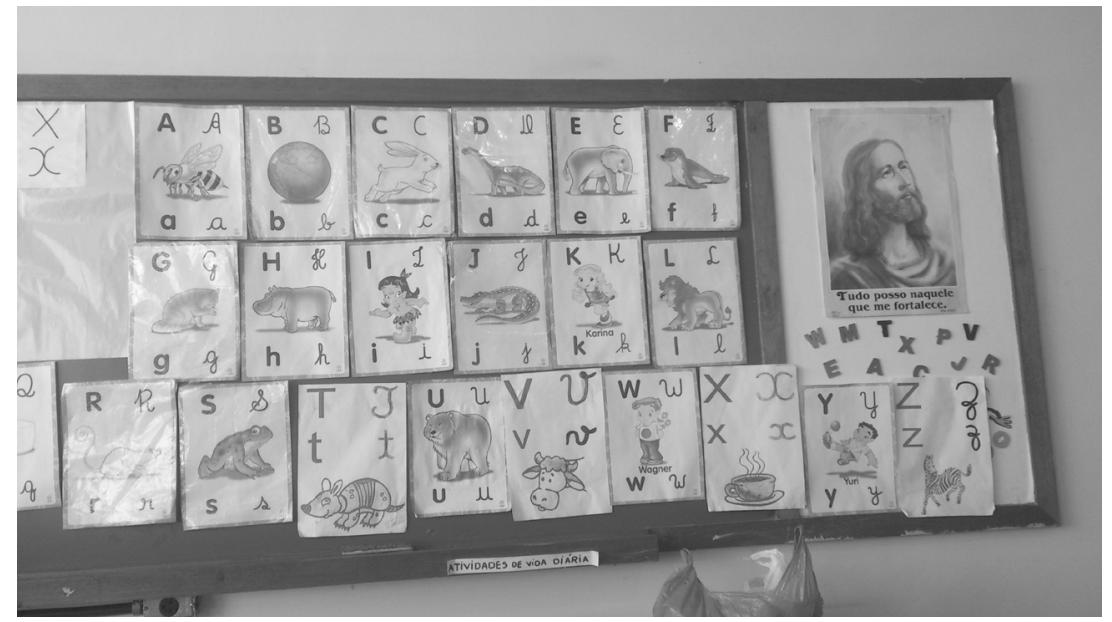

Imagem 4.

Texto Imagem 4: "normalidade-anormalidade..." Fotografia da aluna P.

\section{Quarta cena: o (des)importante... As coisinhas do chão} da escola

Atividade pensada a partir do filme Só dez por cento é mentira ou a (des)biografia de Manoel de Barros. 


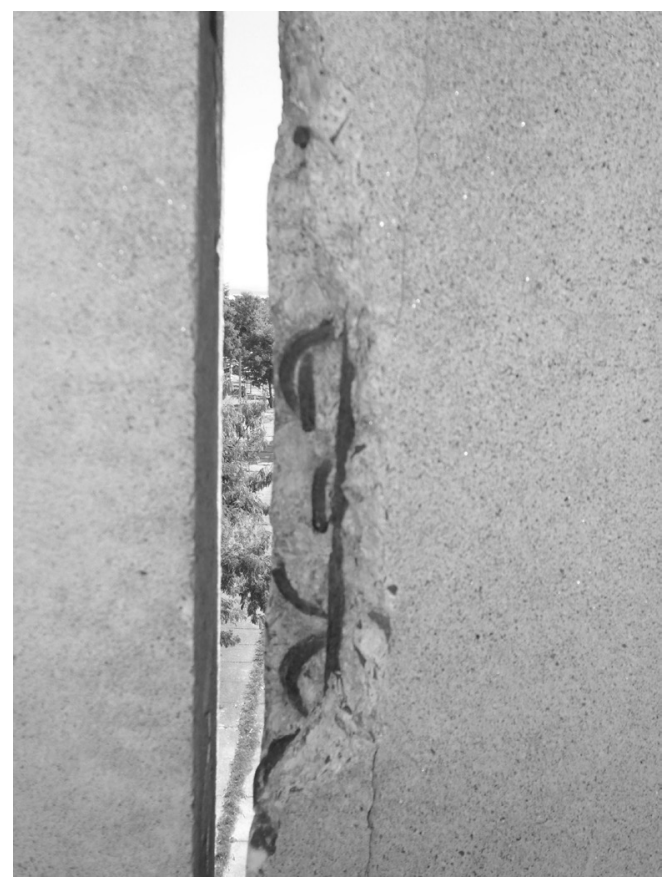

Imagem 5

Texto Imagem 5: O desimportante na escola... Fotografia da aluna T.: "diz Manoel de Barros que a importância de uma coisa não se mede com fita métrica nem com balanças nem barômetros etc. Que a importância de uma coisa há que ser medida pelo encantamento que a coisa produza em nós... Continuamos o nosso trabalho de interação com as crianças e conversa vai e conversa vem, novamente uma coisa me chamou a atenção e me tirou do meu lugar confortável. Era uma fresta... Será que alguém já havia parado para perceber que o lugar ao redor da escola poderia nos oferecer uma paisagem desta? Será que alguém já havia pensando na possibilidade de ir até aquele lugar? Surpresa é encontrar uma coisa que com certeza não havia chamado a atenção de ninguém, não sei o que me fez olhar por aquela fresta, sei apenas que estava procurando algo inusitado e diferente". 
Mas, esses alunos se mostraram também protagonistas e não ficaram apenas como meros espectadores. Eles pediram para usar a câmera e tiraram fotos deles mesmos, dos amigos e até de nós, estagiárias. Pude fotografar outros momentos também de brincadeiras entre eles e até de uma cena inusitada: a "Gabi", Gabriele, estava com uma bota ortopédica no pé direito e um tênis no pé esquerdo, e de repente, para poder brincar, ela simplesmente tirou a bota e enfiou o tênis dentro da bota, virou um "porta-tênis" se assim posso chamar, isso foi bastante inusitado e criativo no meu ponto de vista. Mas como tive que fazer uma escolha de duas imagens, escolhi as fotos que trazem o verde em sua imagem, já que meu astral estava totalmente voltado para a imensidão de possibilidades que a natureza nos oferece. Essa minha visita à escola pode ser resumida com as próprias palavras de Manoel de Barros: "Passava os dias ali, quieto, no meio das coisas miúdas. E me encantei." (2000, p.11)

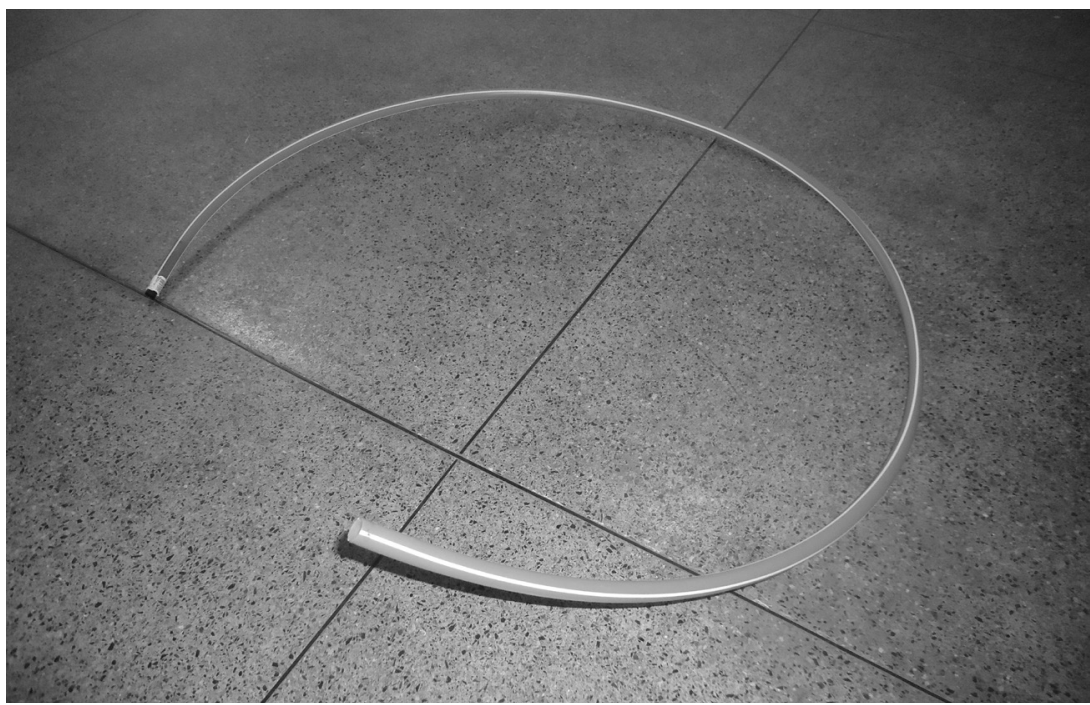

Imagem 6

Texto Imagem 6: O desimportante... Fotografia da aluna M.: “Uma observação que não acontece de forma isolada, e sim paralela ao filme 
que vimos na aula passada Só dez por cento é mentira, sobre Manoel de Barros. O filme trata de uma busca de inspiração na infância e nas coisas "desimportante" presentes em nosso dia a dia ou existentes no mundo. E segue com uma possibilidade poética. A invenção é um negócio profundo. Serve para aumentar o mundo [...] Achei muito difícil a observação, porque, por mais que olhasse, nada a minha volta parecia desimportante. Afinal, se estão ali, se foram inventadas, é porque de alguma forma são importantes, há uma utilidade significativa ao objeto. Comecei a pensar que não havia entendido nada da proposta feita pela professora. Foi, então, que comecei a puxar pela memória o filme e me recordei de uma frase de um poema escrito por Manuel de Barros, que dizia assim: 'as coisas não querem ser vistas por pessoas razoáveis'. Como acredito não ser razoável, fui em busca de objetos que não se limitassem ao seu significado literal e, com um olhar de criança que enxerga em uma simples régua uma avião e no estojo escolar um caminhão de carga, abri meus olhos [...] A princípio um bambolê quebrado. Quebrado porque tentei montá-lo e ele já não encaixava mais. Um brinquedo que a princípio não haveria mais serventia uma vez que um bambolê precisa ser redondo para poder rodar na cintura. Porém, ao olhá-lo com um olhar encantado, vi um telefone onde uma criança poderia falar de um lado e uma outra criança ouviria do outro lado. E, olhando mais atentamente, agora vejo uma corda, quem sabe uma brincadeira de cabo de guerra? Olhando minhas anotações do dia do filme, encontrei a seguinte frase de um dos poemas de Manuel de Barros que exemplifica bem a minha fala: 'O que se diz desimportante pode ser transformado, reaproveitado.'” 


\section{Referências}

BARROS, Manoel de. Ensaios fotográficos. Rio de Janeiro: Ed. Record, 2000.

BRASIL. LDB 9.394/96. Disponível em: http:/ / www2.camara.leg. br/legin/fed/lei/1996/lei-9394-20-dezembro-1996-362578-norma-pl. html. Acesso em: 10 julho 2014.

BRASIL. Política Nacional de Educação Especial na Perspectiva da Educação Inclusiva. MEC. 2008. Disponível em: <http://portal.mec.gov.br/ seesp/arquivos/pdf/politica.pdf>. Acesso em: 7 maio 2012.

CANDAU, Vera.; LELIS, Isabel. A relação teoria-prática na formação do educador. In: CANDAU, V. (Org.). Rumo a uma nova Didática. Petrópolis: Vozes, 1999. p. 56-72.

CLIMAÇO, Julia Campos. Discursos jurídicos e pedagógicos sobre a diferença na Educação especial. Buenos Aires: FLACSO, 2010.

GADAMER, Hans-Georg. Greg. Verdad y método. Salamanca: Ed. Sígueme, 1977.

JANELA DA ALMA. Documental Brasileiro. Direção: João Jardim e Walter Carvalho (2001)

LARROSA, Jorge. Notas sobre a experiência e o saber de experiência. In: CONGRESSO DE LEITURA DO BRASIL, 13., 17 a 20 jul. 2001. Palestra. Campinas, SP. 17 a 20 jul. 2001.

LARROSA, Jorge. Niños atravesando el paisaje. In: LARROSA, Jorge. Educar la mirada: políticas y pedagogías de la imagen. Buenos Aires: Manantial, 2006a. p. 113-134. 
LARROSA, Jorge. Una lengua para la conversación. In: LARROSA, Jorge; SKLIAR, Carlos (Coord.). Entre pedagogía y literatura. Buenos Aires: Miño y Dávila, 2006b. p. 25-40.

PEREZ DE LARA, Nuria. Escuchar el otro dentro de sí. In: SKLIAR, Carlos; LARROSA, Jorge. Experiencia y alteridad en educación. Buenos Aires: Homo Sapiens Ediciones, 2009. p. 45-77.

PEREZ DE LARA, Nuria; CONTRERAS, José. Investigar la experiencia educativa. Madri: Ed. Morata, 2010.

SKLIAR, Carlos. A educação e a pergunta pelos Outros: diferença, alteridade, diversidade e os outros "outros". 2003. Disponível em: <http://www.perspectiva.ufsc.br/pontodevista_05/03_ skliar.pdf>. Acesso em: $1^{\circ}$ mar. 2014.

SKLIAR, Carlos. Poner en tela de juicio la normalidad, no la anormalidad. Políticas y falta de políticas en relación con las diferencias en educación. Revista Educación y Pedagogía, Medellín, Universidad de Antioquia, Facultad de Educación, v. 15, n. 41, p. 1122, 2005.

SKLIAR, Carlos; TÉLLEZ, Magaldy. Conmover la Educación. Buenos Aires: Noveduc, 2008.

SKLIAR, Carlos. Educar la mirada. Entrevista. Revista "Sin puntero". KIPERSAIN, Sergio (Dir.). TOLOSA, Carlos A. (Ed.), n. 3, p. 1-4, jul. 2009.

SÓ DEZ POR CENTO É MENTIRA. Documental brasileiro. Direção: Pedro Cezar (2009).

Recebido em 26/03/2014 Aprovado em 18/06/2014 